\title{
O léxico do vestuário feminino no século XIX: o frolido de sedas na narrativa de José de Alencar
}

Eliane Oliveira da Costa*

Germana Maria Araújo Sales**

\section{Resumo}

Este artigo objetiva apresentar um levantamento do léxico do vestuário feminino no século XIX nas obras $\mathrm{Lu}$ cíola (1862), Diva (1864) e Senhora (1875), de José de Alencar, com intuito de contribuir para a percepção e para 0 entendimento da consciência estética e nacionalista do autor. A escolha desses romances justifica-se pelo fato de configurarem os perfis de mulher traçados por Alencar e por estarem situados no grupo de seus romances urbanos, cuja riqueza vocabular carecia de um estudo dessa natureza. Para a seleção das unidades léxicas pertencentes ao vestir feminino, utilizamos o software WordSmith Tools (versão 5.0). Quanto ao aporte teórico-metodológico, foram consideradas as orientações da lexicologia, disciplina que se dedica ao estudo e à descrição do léxico. Ao término dessa pesquisa, apreendemos o modo como os trajes femininos são explorados, transparecendo de forma grandiosa o compromisso do escritor cearense com a linguagem e com a expressão da realidade sociocultural da época.

Palavras-chave: Vestuário. Léxico. Lexicologia.

\section{Introdução}

Neste trabalho tomamos como objeto de estudo o léxico utilizado por José de Alencar para descrever o vestuário feminino nos romances urbanos Lucíola (1862), Diva (1864) e Senhora (1875), escritos no século XIX. Temos o objetivo de contribuir para a compreensão da

\footnotetext{
Graduada em Letras - Língua Portuguesa (2009) e mestra em Linguística (2012) pela Universidade Federal do Pará. Doutoranda em Estudos Linguísticos pelo Programa de Pós-Graduação em Letras da UFPA, com projeto apoiado pela Coordenação de Aperfeiçoamento de Pessoal de Nível Superior (Capes). Participa dos Projetos Atlas Geossociolinguístico do Pará (ALiPA) e Atlas Linguístico do Brasil (Região Norte), com pesquisa nas áreas de Dialetologia, Sociolinguística e Socioterminologia. E-mail: elianecosta21@yahoo.com.br

** Graduada em Letras pela Universidade Estadual do Ceará (1989). Mestra em Letras: Teoria Literária pela Universidade Federal do Pará (1997). Doutora em Teoria e História Literária pela Universidade Estadual de Campinas (2003). Professora Associada II da Faculdade de Letras, do Instituto de Letras e Comunicação (ILC), da Universidade do Federal do Pará, na Graduação e Pós-Graduação. E-mail: gmaa.sales@gmail.com
}

Data de submissão: set. 2015 - Data de aceite: nov. 2015 http://dx.doi.org/10.5335/rdes.v11i2.5384 
estética e do nacionalismo alencarianos. Isso porque diante da riqueza vocabular e do contexto de produção da vasta obra do autor, colocamo-nos diante da seguinte questão: em que medida o vestuário favorece o ser escritor para José de Alencar?

Sabemos que o século XIX foi palco de acontecimentos que marcaram o esforço do Brasil para conseguir a sua identidade enquanto nação, sendo importante ressaltar que esse esforço

não se esgotava nas transformações políticas, mas se estendia por toda a estrutura social, refletindo-se nas manifestações artísticas e, consequentemente, literárias" (MICHELETTI, 2012, p. 13).

No que tange à literatura, o romantismo foi a expressão máxima, possibilitando o despertar de artistas e intelectuais nacionais para a necessidade de se criar uma identidade genuinamente brasileira, moldada com elementos históricos, culturais e linguísticos próprios. Nesse sentido, para José de Alencar, a língua era a tinta com a qual ele podia pintar 0 quadro das realidades socioculturais de um Brasil emergente. Assim, partimos da hipótese de que o vestuário constitui um importante instrumento de expressão dos ideais alencarianos quanto à linguagem e à nacionalidade.

Isso posto, esclarecemos que essa perspectiva de estudo em que obras literárias são observadas sob um ponto de vista linguístico vem sendo desenvolvida por estudiosos da área da linguagem, sobretudo, por aqueles que se dedicam ao trabalho com o léxico. Nessa perspectiva, no que concerne às obras de José de Alen- car, encontramos trabalhos como os de Godoi (2006), O vocabulário indianista e ideológico de José de Alencar, Queiroz (2006), O vocabulário alencariano de $O$ sertanejo: uma análise léxico-semântica e Ávila e Martins (2008), O léxico indianista em José de Alencar.

Trabalhos dessa natureza, que também é a do que ora apresentamos, justificam-se por uma série de motivos, dentre os quais destacamos, em consonância com Queiroz (2006): pôr em evidência a preocupação dos escritores brasileiros daquela época com a linguagem e com a representação da sociedade brasileira do século XIX, valorizar a escrita e a importância desses escritores para a estruturação de um Brasil que se queria livre do ponto de vista cultural, linguístico e cultural, alargar o rol de estudos sobre o tema; estender a relação entre linguística e literatura; possibilitar aos estudiosos do léxico uma nova forma de estudo e de compreensão desse componente linguístico, contribuir para as pesquisas daqueles que se interessam pelas obras de José de Alencar; colaborar para o ensino de literatura nas salas de aula do ensino médio e da graduação.

Para a realização desta pesquisa, utilizamos as orientações teórico-metodológicas da lexicologia, ciência que se ocupa do léxico e de sua movimentação. O estabelecimento do corpus foi feito com o auxílio do software WordSmith Tools (versão 5.0), programa computacional que proporcionou a identificação dos 
itens lexicais pertencentes ao vestuário feminino. Este estudo vivencia o século XIX, contribuindo, dessa forma, para o entendimento das obras de José de Alencar.

O trabalho apresenta seis seções: na primeira, expomos o léxico, na segunda, abordamos a lexicologia, apontando suas principais funções, na terceira, discorremos humildemente sobre José de Alencar e seus romances urbanos, na quarta, pontuamos algumas considerações a respeito do vestuário, na quinta, descrevemos a metodologia desenvolvida; e, finalmente, na sexta, apresentamos os resultados desta pesquisa.

\section{Aporte teórico da pesquisa}

\section{O léxico}

O léxico é a primeira instância de nomeação do mundo, ou seja, é ele o instrumento de registro da história do conhecimento (ciências e tecnologias) e da humanidade, que se confundem naturalmente. Assim sendo, a produção do conhecimento nessas áreas se dá de maneira constante, transformando e modificando a realidade histórica, social e cultural das civilizações. O caráter inconstante dessa relação (conhecimento/ sociedade) movimenta o léxico que se mantém aberto a transformações, recebendo novas palavras em detrimento do desaparecimento total ou parcial de outras que não nomeiam mais realidades atuais. Sobre o componente lexical das línguas, Biderman explica:
O léxico está associado ao conhecimento e o processo de nomeação em qualquer língua resulta de uma operação perceptiva e cognitiva. Assim sendo, no aparato linguístico da memória humana, o léxico é o lugar do conhecimento sob o rótulo sintético de palavras - os signos lingüísticos (1998, p. 179).

No mesmo sentido, Vilela esclarece que o léxico pode ser visto a partir de duas perspectivas: a cognitivo-representativa, em que é defendido como a "codificação da realidade extralinguística interiorizada no saber de uma dada comunidade linguística”, e a comunicativa, em que é posto como um "conjunto das palavras por meio das quais os membros de uma comunidade linguística comunicam entre si" (1995, p. 13). Nesse sentido, o léxico, por ser o nível linguístico por meio do qual se nomeia e se organiza a realidade individual e social da humanidade, constitui um sistema aberto que absorve de maneira muito dinâmica as transformações resultantes de necessidades de ordens diversas. As palavras de Isquerdo e Carvalho, a seguir, corroboram o exposto:

A língua, como produto social e cultural, veicula crenças e ideologias e, em particular, por meio do léxico, nível da língua que materializa as modificações ocorridas na sociedade, perpetua a visão de mundo dos grupos sociais em diferentes épocas (2012, p. 251).

Por tudo isso, entende-se que o léxico resulta dessa relação que mantém com a sociedade e com a cultura. O estudo desse sistema linguístico, independente do ponto de vista teórico-metodológico adotado, possibilita o conhecimento real e efetivo do modo como as sociedades 
se desenvolveram ao longo da história. Nessa perspectiva, segundo Isquerdo,

[...] o léxico é o nível da língua que melhor evidência as pegadas do homem na sua trajetória histórica. É por meio dele que o homem nomeia o espaço que o circunda e consubstancia a sua visão de mundo acerca da sociedade (2009, p. 43).

\section{A Lexicologia}

A Lexicologia é um campo de estudo que analisa e descreve o léxico geral das línguas naturais. Esse léxico comporta todas as palavras existentes num sistema linguístico, sendo, portanto, a Lexicologia "a disciplina responsável pelo estudo das palavras de uma língua, em discursos individuais e coletivos" (PONTES, 2009, p. 18). Assim, dada a complexidade do seu objeto de estudo, a Lexicologia desenvolve uma série de atividades, dentre as quais se destacam, de acordo com Barbosa, as seguintes:

a) Definir conjuntos e subconjuntos lexicais - universo léxico, conjunto vocabulário, léxico efetivo e virtual, vocabulário ativo e passivo;

b) Conceituar e delimitar a unidade lexical de base - a lexia -, bem como elaborar os modelos teóricos subjacentes às suas diferentes denominações;

c) Analisar e descrever as estruturas morfo-sintáxico-semânticas de tais unidades, sua estruturação, tipologia e possibilidades combinatórias;

d) Examinar as relações do léxico de uma língua com o universo natural, social e cultural;

e) Analisar e descrever as relações entre a expressão e o conteúdo das palavras e os fenômenos daí decorrentes: polissemia, homonímia, homossemia total (sinonímia), homossemia parcial (pa- rassinonímia), hiperonímia, hiponímia, coiponímia, antonímia e paronímia; e

f) Formalizar a dinâmica do léxico e do processo neológico, observadas as fases de criação da palavra, sua aceitabilidade no meio social, sua desneologização e possível reneologização (1990, p. 3).

Como podemos ver, a Lexicologia tem um amplo alcance, envolvendo morfologia lexical, semântica lexical, isto é, forma e sentido, além de combinar em si elementos de etimologia, história das palavras e gramática histórica. Segundo Pontes, ela tem crescido bastante e tomado novos direcionamentos, sobretudo, com as contribuições da Sociolinguística, da Pragmática e da Linguística Cognitiva, disciplinas que possibilitam novas formas de investigar o léxico, tornando temas como neologismos, estrangeirismos, metáfora, polissemia, sinonímia, entre outros, importantes no âmbito das pesquisas linguísticas modernas (2009, p. 19).

\section{José de Alencar e os romances urbanos}

Foi na década de 1850 que os leitores brasileiros tiveram contato com a narrativa de José Martiniano de Alencar, o cearense de Mecejana, radicado na cidade do Rio de Janeiro desde cedo. Alencar principiou a carreira de escritor nas páginas dos jornais e, conforme relata em Como e porque sou romancista (1893), foi a aproximação com as narrativas, como leitor, que transbordou a veia de folhetinista e romancista, tornando-se um dos maiores representantes do ro- 
mantismo brasileiro, pela forma original do trabalho com a ficção. Sobre o processo de criação do romancista, Micheletti assinala:

O criador de Iracema via no trabalho com a palavra a necessidade de precisão, brilho e esmero para concretizar as 'ideias'; as palavras eram para ele como tintas nas mãos do pintor que deveria ter habilidade suficiente para combiná-las com exatidão sobre a tela. De outra parte, havia a convicção de que a existência de uma literatura autônoma passa pela autonomia da linguagem que lhe dá forma. Para o autor, seria necessário aceitar a "aclimação" da língua portuguesa em nosso solo, valorizar as novas formas de dizer e explorar-lhes a expressividade (2012, p. 21).

A narrativa de Alencar foi concebida em um projeto, descrito pelo próprio romancista no prólogo intitulado Bênção paterna (1873), quando descreve a proposta da elaboração dos seus romances disposta em três fases, a primitiva, a histórica e a infância de nossa literatura:

O período orgânico desta literatura conta já três fases. A primitiva, que se pode chamar aborígene, são as lendas e mitos da terra selvagem e conquistada; são as tradições que embalaram a infância do povo, e ele escutava como o filho a quem a mãe acalenta no berço com as canções da pátria, que abandonou. Iracema pertence a essa literatura primitiva, cheia de santidade e enlevo, para aqueles que veneram na terra da pátria a mãe fecunda - alma mater, e não enxergam nela apenas o chão onde pisam. O segundo período é histórico: representa o consórcio do povo invasor com a terra americana, que dele recebia a cultura, e lhe retribuía nos eflúvios de sua natureza virgem e nas reverberações de um solo esplêndido. [...] A ele pertencem o Guarani e as Minas de Prata. Há aí muita e boa messe a colher para o nosso romance histórico; mas não exótico e raquítico como se propôs a ensiná-lo, a nós beócios, um escritor português. A terceira fase, a infância de nossa literatura, começada com a independência política, ainda não terminou; espera escritores que lhe dêm os últimos traços e formem o verdadeiro gosto nacional, fazendo calar as pretensões hoje tão acesas, de nos recolonizarem pela alma e pelo coração, já que não o podem pelo braço. Neste período a poesia brasileira, embora balbuciante ainda, ressoa, não já somente nos rumores da brisa e nos ecos da floresta, senão também nas singelas cantigas do povo e nos íntimos serões da família. O Tronco do Ipê, o Til e o Gaúcho, vieram dali; embora, no primeiro sobretudo, se note já, devido à proximidade da corte e à data mais recente, a influência da nova cidade, que de dia em dia se modifica e se repassa do espírito forasteiro. Nos grandes focos, especialmente na corte, a sociedade tem a fisionomia indecisa, vaga e múltipla, tão natural à idade da adolescência. É o efeito da transição que se opera; e também do amálgama de elementos diversos. A importação contínua de idéias e costumes estranhos, que dia por dia nos trazem todos os povos do mundo, devem por força de comover uma sociedade nascente, naturalmente inclinada a receber o influxo de mais adiantada civilização. Desta luta entre o espírito conterrâneo e a invasão estrangeira, são reflexos Lucíola, Diva, A pata da gazela, e tu, livrinho, que aí vais correr mundo com o rótulo de Sonhos d'Ouro (ALENCAR, 1872, p. 13).

A linguagem, de fato, é o sistema por meio do qual as realidades existentes são descritas. Na Literatura, ela ganha contornos estilísticos que a distingue da linguagem usada no cotidiano, caracterizando de maneira especial escrita dos que a utilizam. Dessa maneira, recursos linguísticos (morfológicos, fonéticos, sintáticos, semânticos e lexicais) são utilizados e engrandecem as obras lite- 
rárias. Essas, por sua vez, constituem um espelho no qual se refletem as mudanças pelas quais a língua passa. Nessa perspectiva, Queiroz, expressa seu entendimento:

Assim, entendemos que a linguagem literária, embora se configure como um uso especial da linguagem, não deixa de ser um ato linguístico, na medida em que o autor, no processo de criação, vale-se, para sua expressão, do sistema da língua por ele utilizada (2006, p. 23).

Desse modo, a Literatura emerge e se constrói na e pela linguagem, o que fica bem perceptível nas obras de José de Alencar, que não se ateve aos padrões literários da época e construiu, também pelos recursos da linguagem, a identidade da nação brasileira que experimentava mudanças significativas, tanto na perspectiva política como na de formação da identidade cultural do povo. As palavras de Micheletti, corroboram o exposto:

Perpassa pela sua vasta obra a consciência de que o escritor tem dois grandes compromissos: um com o seu país, devendo expressar, portanto, em seus contextos, o caráter de seu povo; outro; estético: a mensagem não afrouxar, a palavra é, para o escritor, "ciência" e "arte" - veículo da expressão fiel de ideias revestidas de "graças" e de belezas (2012, p. 33).

No grupo dos romances urbanos, nos quais este estudo foca, segundo Mendes (1965, p. 7), são obras que "tiveram especialmente como cenário a cidade do Rio de Janeiro e seus arredores" e que recriam uma sociedade distinta pela ascenção da burguesia carioca que seguia e copiava os padrões europeus quanto às vestes e à cultura.

Nesse sentido, com relação à movimentação social na corte do Império, Micheletti explica:

No Rio de Janeiro, consolidavam-se as feições adquiridas com a vinda da Família Real no início do século: multiplicavam-se os espetáculos teatrais, os saraus e os bailes dos quais participavam estudantes e moças casadoiras; e a rua do Ouvidor, com suas lojas de artigos importados e hábeis costureiras, transformava-se em símbolo de elegância (2012, p. 27).

Quanto à explosão da moda nos cenários nacional, e internacional, o seguinte excerto é esclarecedor:

O século XIX foi o século da explosão da moda ou o século da moda por excelência. Nele ela atinge um maior núcleo de pessoas, da pequena e média burguesia da França e da Inglaterra 'à boa sociedade' de lugares distantes como o Rio de Janeiro, onde, a partir de então, se tem acesso quase simultâneo às novidades estrangeiras. No Rio de Janeiro, as transformações no espaço urbano, a europeização dos costumes, o incremento do comércio e a intensificação da vida social são elementos que servem de pano de fundo para a difusão da moda (APARÍCIO, 2008, p. 3-4).

Assim sendo, o escritor cearense nasceu, viveu e escreveu em um período

[...] de intenso e movimentado desenvolvimento do Brasil, e soube ele com admirável maestria fixar essa época nas suas peças de teatro e em muitos de seus romances que constituem verdadeiro documentário da vida brasileira do segundo reinado (MENDES, 1965, p. 7). 


\section{Vestuário e identidade: breves considerações}

É inegável que o vestuário tem papel importante na formação da identidade individual e coletiva de uma nação. Assim como idioletos e dialetos podem, respectivamente, identificar indivíduo e povo, vestimentas conseguem evidenciar países, regiões, cidades, classes e grupos sociais. O fragmento, a seguir, amplia o entendimento sobre a relação do vestuário com a cultura e com a linguagem:

O vestuário tem uma dupla origem, simbólica e instrumental. Simbólica, pois situa-se ao lado da linguagem e da arte; como objeto faz parte do conjunto de instrumentos através dos quais o homem interfere no ambiente natural, ou seja, no domínio da cultura material. Agindo como linguagem que faz circular a informação transmitida pelo vestuário entre indivíduos e grupos, reforça o conceito de individualidade e de identidade. Em todos os grupos sociais o vestuário é um meio de criar e manter identidade, surgindo como um objeto restaurador em todas as mudanças sociais e culturais vivenciadas pelas mulheres. A constituição deste objeto como documento ocorre a partir do contexto social em que ele se encontra inserido (BARTHES apud BORGES, 2013, p. 4).

O modo como o vestuário marca a época em que é criado também é discutido por outros autores:

Por séculos, indivíduos e sociedades têm usado o vestuário e outros adornos como forma de comunicação não-verbal para indicar ocupação, posição social, localidade, disponibilidade sexual ou afiliação a determinado grupo (COBRA, 2007, p. 9 apud TAVARES, 2009, p. 12).
O vestuário é sempre significativo e em suas interpretações aproximamo-nos da organicidade da sociedade que o produziu. Afinal em seus cortes, cores, texturas, comprimentos, exotismo, as roupas dão conta de imprimir sobre os corpos que as transportam categorias sociais, ideais estéticos, manifestações psicológicas relações de gênero e de poder (CRANE, 2013, p. 22 apud BORGES, 2013, p. 4).

Tavares, a partir do ponto de vista de Lipovetsky (1989), afirma ainda que:

[...] a moda serve como reflexo da sociedade de um determinado período e traduz a gama de complexidade e referências sociais, psicológicas e comportamentais (TAVARES, 2009, p. 14).

De modo que existe um vestuário que atende ao seu povo em cada época.

$\mathrm{O}$ autor, neste sentido, com base em Kölher (2001), Laver (1997), Braga (2007), Moutinho e Valença (2000), Cobra (2007) e Baudot (2002), discorre sobre a história da moda, explicando, por exemplo, que o drapeamento era a principal característica da roupa usada pelos egípcios e que entre gregos e romanos, os drapeados, muito elaborados e marcantes, especificavam a indumentária clássica, sendo a túnica de linho (quitão), uma sobreveste de lã (peplo) e uma capa de lã (clâmide), as principais peças gregas. As tendências de cada período, às vezes, voltam e ouvimos que certo estilista se inspirou no século tal para elaborar as peças de sua coleção, que a festa de determinado amigo será no estilo anos 1980, etc., permitindo, de uma forma ou de outra, que as épocas sejam revividas. 


\section{Procedimentos metodológicos}

\section{Seleção das obras}

José de Alencar é um escritor de vasta produção literária. Desse modo, entre os gêneros produzidos pelo romancista, focamos no romance e, dentro desse, nos romances urbanos Lucíola, Diva e Senhora por configurarem o que na literatura denominam de perfis de mulher. As obras foram obtidas em formato PDF por meio do portal Domínio Público (disponí- vel em: <http://www.dominiopublico.gov. br/pesquisa/PesquisaObraForm.jsp >).

\section{Estabelecimento e validação do corpus}

Os textos em PDF foram convertidos para o formato TXT para que pudessem ser tratados no WordSmith Tools (versão 5.0), programa computacional que, por meio da ferramenta WordList, permite gerar uma lista com todas as palavras do texto analisado, conforme a Ilustração 1:

Ilustração 1 - Gerando lista de palavras

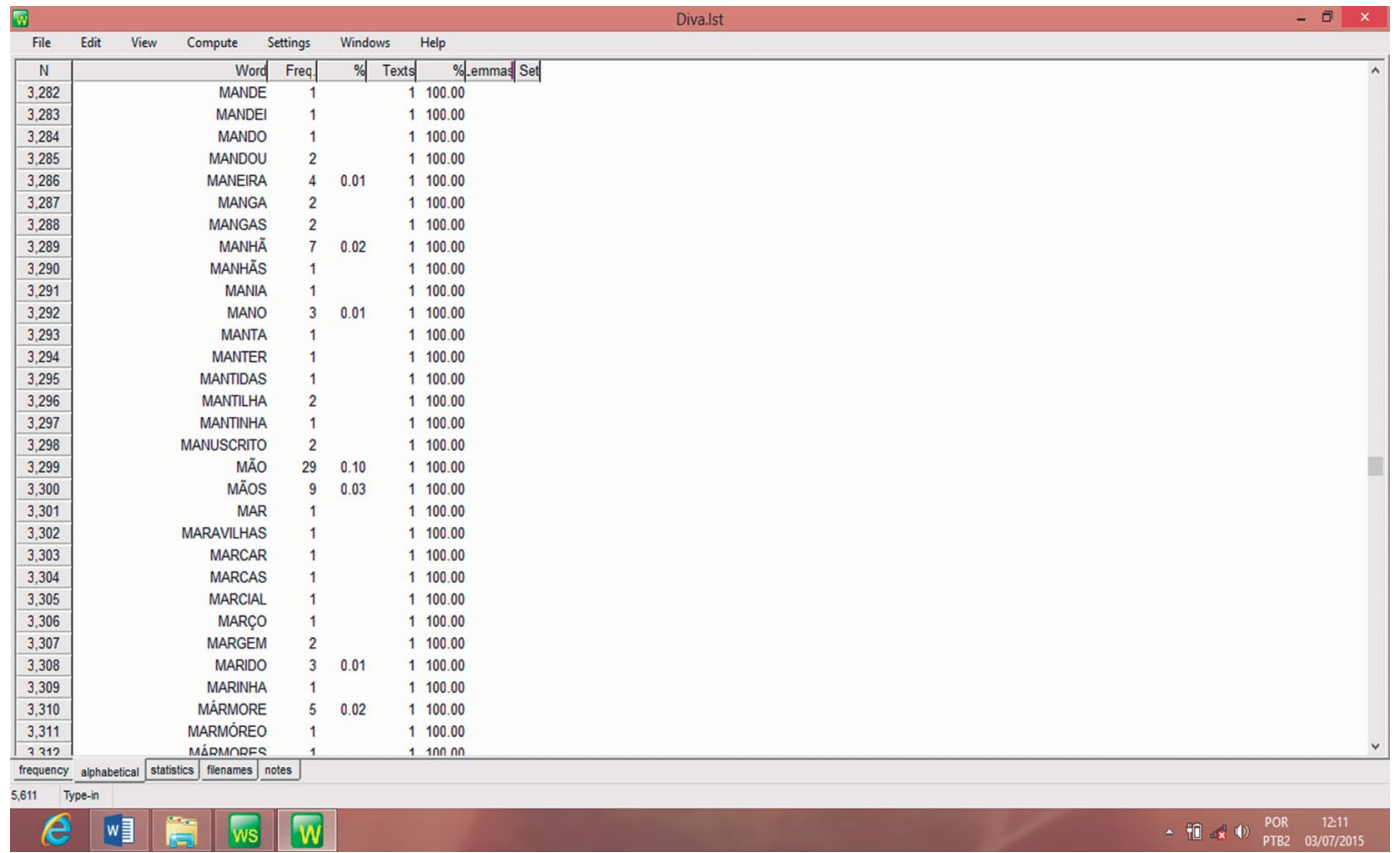

Fonte: dos autores.

Após rodarmos as três obras estudadas, tal como foram obtidas, chegamos a um total de 24.410 palavras, sendo 5.611 de Diva, 7. 762 de Lucíola e 11.337 de Senhora. Em seguida, passamos à aná- lise individual das listas, indo direto à procura de substantivos cujos referentes fossem vestes femininas, desconsiderando as partes das peças como forro, manga, ombreira, fimbria, etc., e à seleção de 
seus contextos de ocorrência (abonação), o que foi feito com o auxílio da ferramen- ta Concord do mesmo software, como apresentado na Ilustração 2 :

Ilustração 2 - Selecionando os contextos de ocorrência das palavras

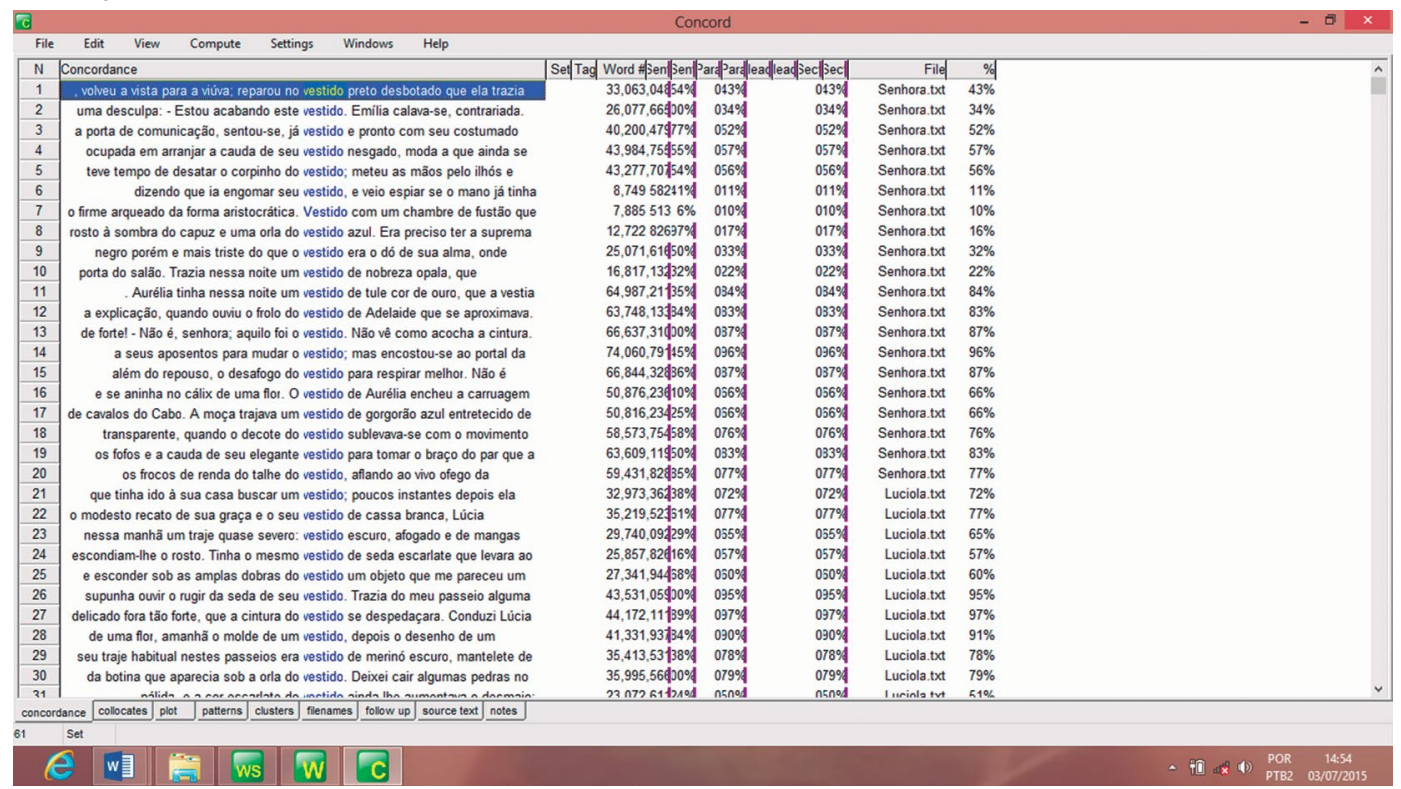

Fonte: dos autores.

Como observamos, o programa lista todos os contextos de uso da palavra analisada e informa o número de vezes que ela aparece em cada uma das obras. Avaliamos todos eles e selecionamos um em cada um dos textos para que pudéssemos escolher quanto à representatividade estética, valendo explicar que algumas palavras não acontecem nos três textos literários. Por fim, para as abonações, elegemos somente um dos trechos relacionados e usamos os códigos ADI (Alencar/Diva), ALU (Alencar/Lucíola) e ASE (Alencar/Senhora), seguido do número da página, para identificá-las.

\section{Decisões para a apresentação das entradas}

Dada a intenção e a dimensão deste estudo, trabalhamos apenas com substantivos; contamos a ocorrência das palavras estudas sem levar em consideração a categoria gramatical de número e as vezes em que elas apareciam fazendo referência ao vestuário masculino, apresentamos os vocábulos em ordem alfabética e no singular, desconsideramos aspectos de polissemia, relações de hiperonímia e/ou quaisquer outros fenômenos dessa natureza, o que foi feito também quando da seleção dos trechos abonatórios, utilizamos apenas Ferreira (2009) para a 
coleta das definições e consultamos um blogue de moda histórica (disponível em: <modahistorica.blogspost.com>) para a redação das notas informativas, que aparecem em alguns verbetes.

\section{Apresentação e análise dos resultados}

Ao fazermos o levantamento do léxico do vestuário feminino em Diva, Lucíola e Senhora, chegamos a um total de vinte itens lexicais, distribuídos segundo Gráfico 1.

Gráfico 1 - Peças do vestuário feminino por obra

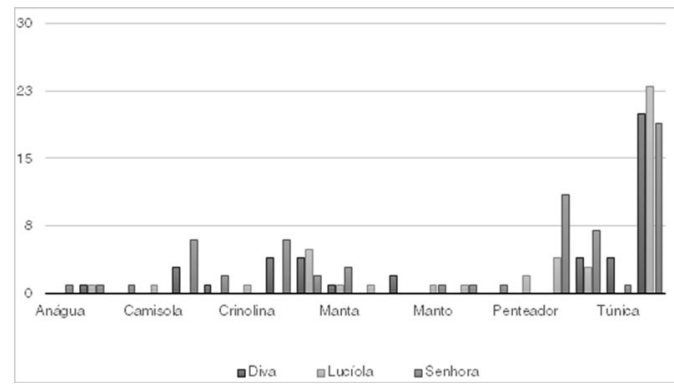

Fonte: dos autores.

Antes de os relacionarmos, consideramos importante mostrar a variedade de tecidos utilizados por José de Alencar nas três obras pesquisadas, consoante Gráfico 2.
Gráfico 2 - Tecidos por obra

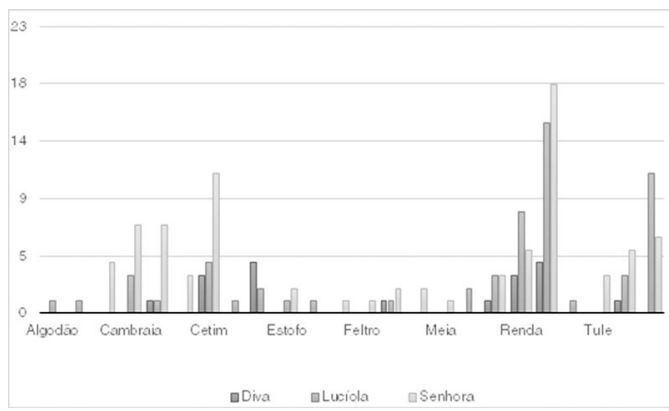

Fonte: dos autores.

1) Anágua - s. f.

Saia usada sob o vestido ou outra saia, em geral mais curta que estes; saia de baixo.

"Os lindos cabelos negros refluíam-lhe pelos ombros presos apenas com $o$ aro de ouro, que cingia-lhe a opulenta madeixa; o pé escondia-se em um pantufo de cetim que às vezes beliscava a orla da anágua, como um travesso beija-flor" (ASE, p. 40).

Nota: 0 uso da anágua (petticoat) ganhou força em 1585, quando as mulheres começaram a usá-la com o intuito de modificar o formato de seus corpos. $\mathrm{O}$ volume e a dureza da peça arrumavam a saia de cima em formato de abóbada, dando-lhes a intenção de que tinham uma cintura mais fina. Até 1870 ainda usava-se muito anágua, mas, quando o bustle entrou na moda, a peça se tornou decadente.

2) Calça - s. f.

Peça externa do vestuário tanto masculino quanto feminino, que parte da cintura, ou logo abaixo dela, e, contornando o corpo, se fecha no centro junto às virilhas, 
dividindo-se em duas partes, que irão contornar e cobrir separadamente as pernas, descendo, por via de regra, até os tornozelos.

"Quando o vento que entrava pela janela erguia indiscretamente a fímbria da saia, apesar do movimento rápido que a conchegava, descobria-se a volta bordada de uma calça estreita, cerrando o colo esbelto da perna divina" (ALU, 75).

Nota: o uso de calça no século XIX constitui um tema muito controverso, pois em sua base existia a questão ideológica da diferença entre gêneros. Assim, a peça era permitida em escolas, faculdades e sanatórios, como uniforme para a prática de exercícios, e em locais onde as mulheres podiam praticar esportes sem serem vistas. As calças femininas só foram aceitas na década de 1970, quando passaram a significar a independência feminina na moda.

\section{3) Camisa - s. f.}

Peça do vestuário masculino usada por cima da pele ou de camiseta, que vai do pescoço até as coxas.

"Trazia Aurélia uma túnica de cetim verde, colhida à cintura por um cordão de torçal de ouro, cujas borlas tremiam com seu passo modulado. Pelos golpeados deste simples roupão borbulhavam os frocos de transparente cambraia, que envolviam as formas sedutoras da jovem mulher. As mangas amplas e envazadas eram apanhadas, na covinha do braço e sobre a espádua, por um broche onde também prendia a ombreira, mostrando o braço mimoso, cuja tez roseava a camisa de cambraia abotoada no punho por uma pérola" (ASE, p. 40).

Nota: o uso de camisa é registrado no século XIX no vestuário chamado alternativo, usado por mulheres, sobretudo americanas, que trabalhavam fora de casa e que eram vistas à margem da sociedade. Tal vestuário incorporava itens do vestuário masculino esportivo inglês como gravatas, chapéus, paletós, camisas, etc., sempre combinados com peças femininas da moda. As francesas, também o adotaram, com o nome de tailler ("conjunto sob medida") e o usavam para viajar (classe média) e para trabalhar (classe operária). Contudo, em meados do século XIX, o paletó foi abraçado pelas altas classes, sendo usado no campo ou no litoral, e a peça determinante do traje feminino surgiu nos EUA, em 1870, a chemisier, uma camisa masculina adaptada, ornamentada com uma pequena gravata borboleta na cor preta.

\section{4) Camisola - s. f.}

Vestimenta feminina para dormir, semelhante a um vestido, com mangas ou sem elas, e cujo comprimento varia de acordo com a moda.

"Poucos momentos depois de entrar ela foi ao toucador e voltou em traje de dormir; os cabelos soltos e uma longa camisola de linho, sem uma renda, nem um bordado" (ALU, p. 85). 
5) Capa - s. f.

Peça do vestuário usada sobre toda a outra roupa a fim de protegê-la, ou proteger quem a veste, contra a chuva.

"Emília estava defronte, além da cerca de espinheiros que dividia o meu jardim da sua chácara. Uma capa de caxemira escura cobria-lhe quase todo o vestido, e o capuz meio erguido moldurava graciosamente seu rosto divino" (ADI, p. 42).

\section{6) Corpinho - s. m.}

Roupa íntima feminina em forma de corpete.

"Trazia o vestido de alvas escumilhas, com a saia rofada de largos folhos. Pequenos ramos de urze, com um só botão cor de rosa, apanhavam os fofos transparentes, que o menor sopro fazia arfar. $\mathrm{O}$ forro de seda do corpinho, ligeiramente decotado, apenas debuxava entre a fina gaza os contornos nascentes do gárceo colo; e dentre as nuvens de rendas das mangas só escapava a parte inferior do mais lindo braço" (ADI, p. 15).

\section{7) Crinolina - s. f.}

Anágua de crinolina, usada para armar ou entufar a saia.

"Figure uma moça vestida de ricas sedas, com as mangas enroladas e a saia arregaçada e atada em nó sobre o meio da crinolina; com uma toalha passada pelo pescoço à guisa de avental; vermelha pelo calor e reflexo do fogo, batendo gemas de ovos para fazer não sei que doce" (ALU, p. 83).

Nota: o uso de crinolina foi efetivo em várias classes sociais. $\mathrm{O}$ tamanho da crinolina chegou a três metros de diâmetro, causando dificuldades para as mulheres passarem em portas, entrarem nas carruagens, etc. Mais tarde, a peça se tornou mais leve, uma vez que passaram a ser feitas de aço e que exigiam um número menor de anáguas. Por baixo da gaiola de crinolina, havia muita liberdade para as pernas e, para que estas não ficassem visíveis, por conta da facilidade de movimento da peça, as mulheres tinham de vestir calças e botas acima do tornozelo.

\section{8) Lenço - s. m.}

Pedaço quadrado de tecido que serve para uma pessoa se assoar, ou para ornar e resguardar a cabeça ou o pescoço.

"E apanhando seu lenço de rendas que jazia sobre o sofá, olhou-o como se buscasse nele explicação daquela singular pergunta do marido" (ASE, p. 117).

\section{9) Luva - s. f.}

Peça do vestuário que se ajusta à mão e aos dedos, para agasalho, adorno, proteção ou higiene.

"Oh! Essa mão gentil, quando ela a despia da luva, tinha uma alma; movia-se em torno de sua beleza, como um anjo que descera do céu para acariciá-la. Aos toques suaves 
dos dedos mágicos parecia que sua lindeza debuxava-se mais brilhante" (ADI, p. 52).

\section{0) Manta - s. f.}

Grande pano de lã, do feitio de um cobertor, e que serve para agasalhar. "Lúcia, trançando a sua longa manta listrada de escarlate, que a envolveu como um pálio romano, voltara ao seu lugar e amolgara sobre a cadeira um corpo sem articulações" (ALU, p. 32).

\section{1) Mantelete - s. f.}

Pequena capa, leve e com rendas, para senhora.

"O seu traje habitual nestes passeios era vestido de merinó escuro, mantelete de seda preta, e um chapéu de palha com laços azuis. Mas essa mulher tinha a beleza luxuosa que se orna a si mesma e os enfeites, longe de realçar, amesquinham; nunca ela me parecia mais linda do que sob essa simplicidade severa.” (ALU, p. 91)

\section{2) Mantilha - s. f.}

Manta para a proteção dos ombros e da cabeça.

"Não via Emília; procurava-a nas quadrilha já formadas, quando ela surgiu diante de nós, envolta em uma ampla mantilha cor de cinza, que lhe ocultava todo o corpo e cingia com uma das pontas o colo e parte da cabeça" (ADI, p. 17).

\section{3) Manto - s. m.}

Capa de cauda e roda que se prende nos ombros.

"Envolvia-a desde a cabeça até aos pés um finíssimo e amplo manto de alva caxemira, que apenas descobria-lhe o fino rosto à sombra do capuz e uma orla do vestido azul. Era preciso ter a elegância de Aurélia para dentre esse envolto singelo e fofo, desatar o talhe dum garbo encantador" (ASE, p. 23).

\section{4) Pelica - s. f}

Pele fina, curtida e preparada para luvas, calçados, etc.

"Pela porta fronteira acabava de entrar Aurélia, em companhia de D. Firmina. A moça trazia nos ombros uma pelica de caxemira cinzenta, que disfarçava seu traje de noiva, cingindo-lhe a cabeça com o frouxo capuz" (ASE, p. 38).

\section{5) Peliça - s. f.}

Peça do vestuário, ou colcha, feita ou forrada de peles.

"Ali, naquele carro, ou nas salas onde entravam, parecia-lhe que sua posição e sua importância eram a mesma, senão menor, do que tinha o leque, a peliça, as jóias, o carro, no traje e luxo de Aurélia" (ASE, p. 89).

Nota: $o$ uso de roupas de pele estiveram em destaque em todo o século, tendo como característica as nesgas de pele para passar os braços. 


\section{6) Penteador - s. m.}

Roupão ou espécie de toalha que se põe nos ombros de quem se penteia ou corta o cabelo.

"Até que o penteador de veludo voou pelos ares, as tranças luxuriosas dos cabelos negros rolaram pelos ombros arrufando ao contato a pele melindrosa, uma nuvem de rendas e cambraias abateu-se a seus pés, e eu via aparecer aos meus olhos pasmos, nadando em ondas de luz, no esplendor de sua completa nudez, a mais formosa bacante que esmagara outrora com o pé lascivo as unhas de Corinto" (ALU, p. 14).

\section{7) Roupão - s. m.}

Peça caseira de vestuário, longa e confortável, aberta na frente, de mangas compridas e cinto, usada sobre a roupa de dormir ou sobre a roupa debaixo, ou para ficar à vontade.

"Envolvia o corpo da moça um roupão de cambraia, as pregas caíam sobre o tapete semelhantes aos borbotões da nívea espuma de uma cascata, e deixavam-lhe o talho debuxado sob a fina teia de linho." (ALU, p. 40)

\section{8) Saia - s. f.}

Parte do vestuário feminino que desce da cintura sobre as pernas até uma altura variável, constituindo ou não uma peça independente.
"Moderando os arrojos dessa instrumentação vertiginosa, para fazer o acompanhamento, a moça começou a cantar; mas às primeiras notas, sentindo-se tolhida pela posição, abandonou o piano, e em pé, no meio da sala, roçagando a saia do roupão como se fosse a cauda do pálio gaulês, ela reproduziu com a voz e o gesto aquela epopeia do coração traído, que tantas vezes tinha visto representada por Lagrange" (ASE, p. 6).

\section{9) Túnica - s. f.}

Antigo vestuário, longo e ajustado ao corpo.

"Trazia Aurélia uma túnica de cetim verde, colhida à cintura por um cordão de torçal de ouro, cujas borlas tremiam com seu passo modulado. Pelos golpeados deste simples roupão borbulhavam os frocos de transparente cambraia que envolviam as formas sedutoras da jovem mulher" (ASE, p. 39).

\section{0) Vestido - s. m.}

Vestimenta feminina usada, em geral, por cima da roupa debaixo e composta de saia e blusa, formando um todo.

"Aurélia tinha nessa noite um vestido de tule cor de ouro, que a vestia como uma gaze de luz. Com o voltear da valsa, as ondas vaporosas da saia e a manga roçagante do braço que erguera para apoiar- 
-se em seu par, flutuavam como nuvens diáfanas embebidas de sol, e envolviam a ela e ao cavalheiro como um brilhante arrebol" (ASE, p. 112).

Nota: o vestido, pelo o que temos pesquisado, foi, sem dúvida, a peça mais importante do vestuário feminino no século XIX. A inspiração para sua confecção vem de períodos como a antiguidade clássica, gótico, rococó. Desta forma, dentro dos padrões da época, a peça apresentou diferentes modelos quanto à leveza, localização da cintura, mangas, golas, saias, quantidade de anáguas, etc.

Entendemos que o léxico acima descrito, representa muita bem o modo como as mulheres se vestiam no século XIX, haja vista que o vestido, pelos números desta pesquisa e pelo grau de detalhes com que ele é descrito, foi a peça mais importante do vestuário feminino dessa época. As mulheres alencarianas são sempre bem-sucedidas financeiramente e esbanjam beleza, riqueza e poder, qualidades que podem definir a sociedade brasileira daquela época. $\mathrm{O}$ vestuário feminino em José de Alencar ajuda a tornar as cenas mais ricas e românticas, além de ser veículo de expressão do estado de espírito das personagens e das situações por elas vivenciadas. Tudo é "pintado" pelo autor de Iracema com capricho, o que demonstra a sua preocupação com a seleção vocabular e, consequentemente com a capacidade de expressão da linguagem; da variedade brasileira da língua portuguesa.

\section{Considerações finais}

Neste artigo, realizamos um levantamento do léxico de José de Alencar para o vestuário feminino nos romances urbanos Diva, Lucíola e Senhora, com o objetivo de oferecer uma contribuição à valorização e à compreensão das obras do autor. Assim, chegamos a um conjunto com vinte palavras cujos referentes são muito bem explorados, o que confirma a nossa hipótese de que o vestuário foi um recurso por meio do qual o autor de Iracema pode expressar a sua estética e o seu nacionalismo. Observamos também que a ampliação do universo lexical desta pesquisa, incluindo acessórios para cabelo e roupas, joias, calçados, tipos e partes de roupas e, por que não, o vestuário masculino, possibilitaria um resultado mais abrangente e completo, mas, dada a extensão desse gênero, não pudemos nos estender. Outra forma de expandir os resultados aqui mostrados seria fazer uma pesquisa sobre a natureza e a origem dos tecidos, cujos usos, sem dúvida, nos chamaram a atenção. Além disso, seria interessante uma investigação histórica a respeito da evolução das peças encontradas, meta alcançada parcialmente com a apresentação das informações dessa natureza em notas informativas. 


\section{Le lexique du vêtement} féminin au XIX ${ }^{\mathrm{e}}$ siècle: le fleuri de la soie dans la narrative de José de Alencar

\section{Résumé}

L'objectif de cet article est de présenter un recueil du lexique de vêtements féminins au XIX ${ }^{\mathrm{e}}$ siècle dans les oeuvres « Luciola » (1862), " Diva »(1864), et "Senhora » (1875), de José de Alencar, visant à contribuer à la perception et à la compréhension de la conscience esthétique et nationaliste de l'auteur. Le choix de ces romans est justifié par le fait qu'ils ont mis en évidence les profils de la femme décrite par Alencar et parce qu'ils sont situés dans le groupe de ses romans urbains, dont la richesse du vocabulaire méritait une telle étude. Pour la sélection des unités lexicales appartenant aux habits féminins, on a utilisé le logiciel informatique WordSmith Tools (version 5.0). Quant à l'apport théorique et méthodologique, on a considéré les lignes directrices de la Lexicologie, c'est-à-dire, la discipline consacrée à l'étude de la description du lexique. À la fin de cette recherche, on a saisi la façon dont les tenues sont explorées, en montrant l'engagement de l'écrivain du Ceará avec le langage et l'expression de la réalité socio-culturelle de l'époque.

Mots-clés: Vêtements. Lexique. Lexicologie.

\section{Nota}

Este trabalho foi idealizado e concebido a partir do desejo de adentrar em mais uma das ciências que se dedicam ao estudo do léxico, componente linguístico ao qual temos nos dedicado desde a graduação, investigando-o sob uma perspectiva geossociolinguística e socioterminológica, e de prestigiar as obras de José de Alencar, escritor brasileiro pelo qual mantemos grande admiração.

\section{Referências}

ALENCAR, José Martiniano de. Diva. Disponível em: <http://www.dominiopublico.gov. br/pesquisa/PesquisaObraForm.jsp >. Acesso em: 29 dez. 2014.

ALENCAR, José Martiniano de. Sonhos d'Ouro. Rio de Janeiro: Garnier, 1872.

. Luciola. 12. ed. São Paulo: Ática, 1988. Disponível em: <http://www.dominiopublico.gov.br/pesquisa/PesquisaObraForm. jsp>. Acesso em: 29 dez. 2014.

. Senhora. 4. ed. [s. 1.]: Melhoramentos, [19--]. Disponível em: <http://www. dominiopublico.gov.br/pesquisa/PesquisaObraForm.jsp>. Acesso em: 29 dez. 2014.

APARÍCIO, Letícia Ricci. Forma e aparência: análise da moda feminina e seus sentidos sociais na Ribeirão Preto da Belle Èpoque - 1883-1930. In: ENCONTRO REGIONAL DE HISTÓRIA: PODER, VIOLÊNCIA E EXCLUSÃO, 19., 2008, São Paulo. Disponível em: <http://www.anpuhsp.org.br/sp/downloads/CD\%20XIX/PDF/Autores\%20e\%20 Artigos/Leticia\%20\%20Riccil.pdf > . Acesso em: 11 maio 2015.

BARBOSA, Maria Aparecida. Lexicologia, lexicografia, terminologia, terminografia, identidade científica, objeto, métodos, cam- 
pos de atuação. 1990. Disponível <http:// www.riterm.net/actes/2simposio/barbosa2. htm>. Acesso em: 24 out. 2011.

BARBOSA, Maria Aparecida. Lexicologia, lexicografia, terminologia, terminografia, identidade científica, objeto, métodos, campos de atuação. In: SIMPÓSIO LATINO-AMERICANO DE TERMINOLOGIA, 2., ENCONTRO BRASILEIRO DE TERMINOLOGIA TÉCNICO CIENTÍFICA, 1., 1990, Brasília. Anais... Brasília: União Latina, CNPq, IBICTI, 1990.

BIDERMAN, M. T. A face quantitativa da linguagem: um dicionário de frequências do português. Alfa, São Paulo, v. 42, n. especial, p. 161-181, 1998. Disponível em: <seer.fclar. unesp.br/alfa/article/view/4049>. Acesso em: 17 ago. 2011.

BORGES, Letícia Oliveira. Influências e representações no vestuário feminino: a representação nos livros didáticos de história. Revista Latino-Americana de História, Porto Alegre, n. 6, v. 2, ago. 2013. Disponível em: <http://projeto.unisinos.br/rla/index.php/ rla/article/viewFile/221/175 > . Acesso em: 11 maio 2015.

ENCONTRO BRASILEIRO DE TERMINOLOGIA TÉCNICO CIENTÍFICA, 1., 1990, Brasília. Anais... Brasília: União Latina, CNPq, IBICTI, 1990.

ENTENDA DE MODA. Disponível em: $<$ http://www.entendademoda.com.br>. Acesso em: 11 maio 2015.

FERREIRA, Buarque de Holanda. Novo dicionário Aurélio da língua portuguesa. Curitiba: Positivo, 2009.

ISQUERDO, Aparecida Negri. O caminho do rio, o caminho do homem, o caminho das palavras. In: RIBEIRO, Silvana Soares Costa; COSTA, Sônia Bastos Borba; CARDOSO, Suzana Alice Marcelino (Org.). Dos sons às palavras: nas trilhas da língua portuguesa. Salvador: EDFBA, 2009. p. 41-59.

ISQUERDO, Aparecida Negri; CARVALHO, Paola Mahyra de Oliveira. Léxico e ambiente rural: um estudo de designações para "trabalhador de enxada em roça alheia" no Centro-Oeste do Brasil. In: MOTA, Jacira Andrade; CARDOSO, Suzana Alice Marcelino; PAIM, Marcela Moura Torres (Org.). Documentos 3 - Vozes do X WorkaLiB/Amostras do português brasileiro. Salvador: Vento Leste, 2012. p. 251-261.

MENDES, Oscar. José de Alencar: romances urbanos. Rio de Janeiro: Agir, 1965.

MICHELETTI, Guaraciaba. $O$ discurso $l i$ terário em Alencar: as vozes de consciência estética e nacionalista. São Paulo: Terracota, 2012.

MODA HISTÓRICA. Disponível em: <http:// modahistórica.blogspost.com >. Acesso em: 11 maio 2015.

PONTES, Antônio Luciano. Dicionário para uso escolar: o que é e como se lê. Fortaleza: EdUECE, 2009.

QUEIROZ, Silvana Rodrigues de Souza. $O$ vocabulário alencariano de $O$ sertanejo: uma análise léxico-semântica. 2006. 363 f. Dissertação (Mestrado em Linguística) Programa de Pós-Graduação em Linguística, Universidade Federal de Uberlândia, Minas Gerais, 2006.

TAVARES. Valcenir Maria Maccari. Estudo da criatividade na moda do vestuário feminino. 2009. 78 f. Monografia (Pós-Graduação em Moda, Criação e Processo Produtivo) Universidade do Extremo Sul Catarinense, Criciúma, 2009.

VILELA, Mário. Léxico e gramática. Coimbra: Almedina, 1995. 


\section{Anexo}

ANÁGUA

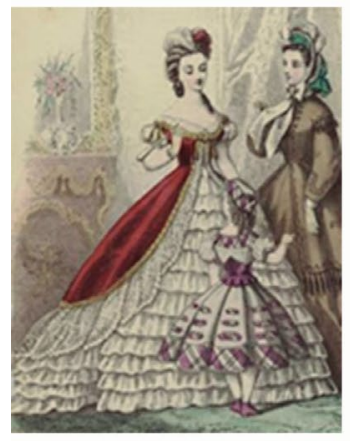

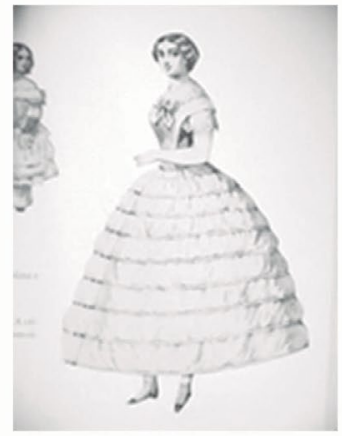

CALÇA
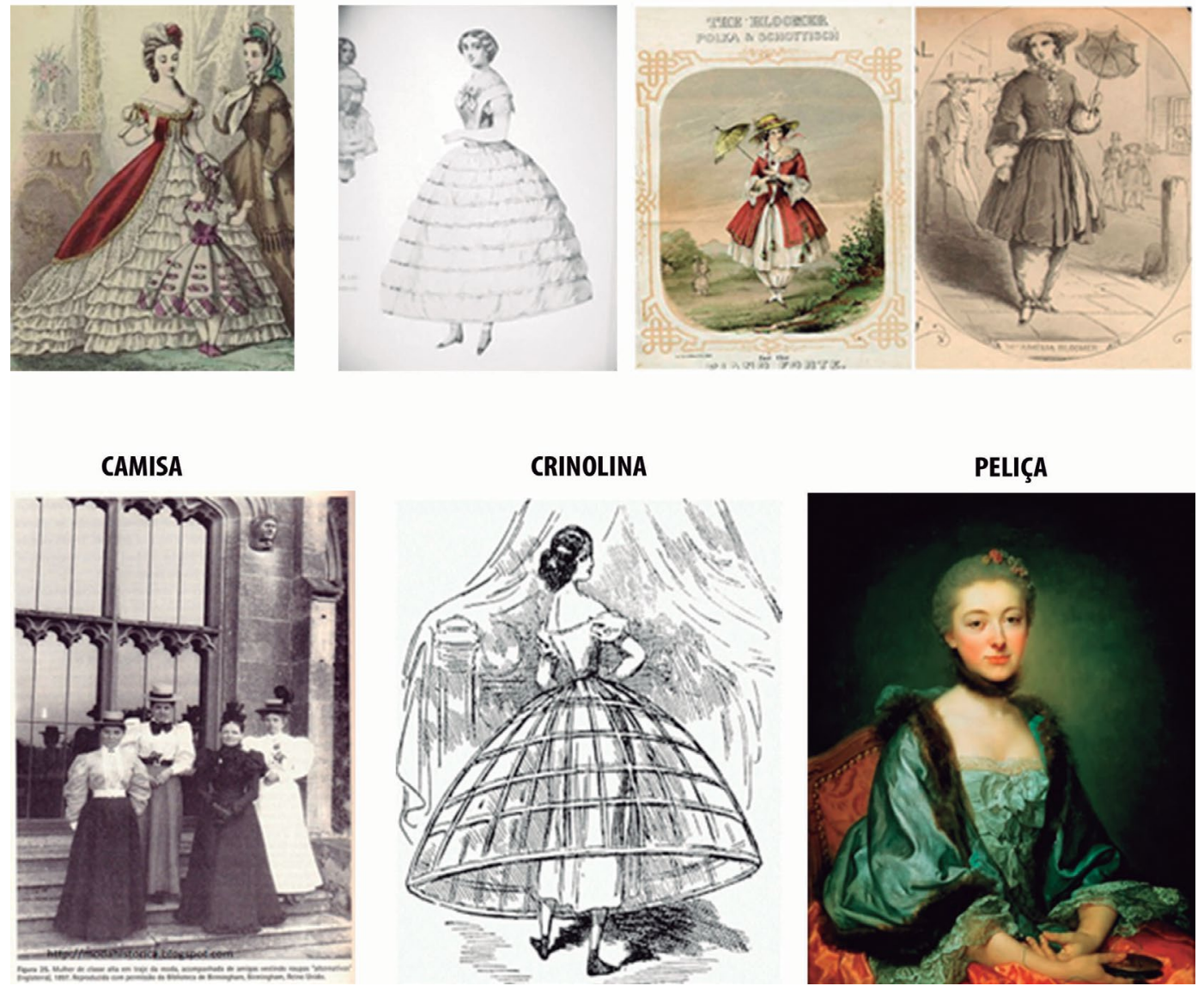

Fonte: disponível em: <modahistórica.blogspost.com>. 


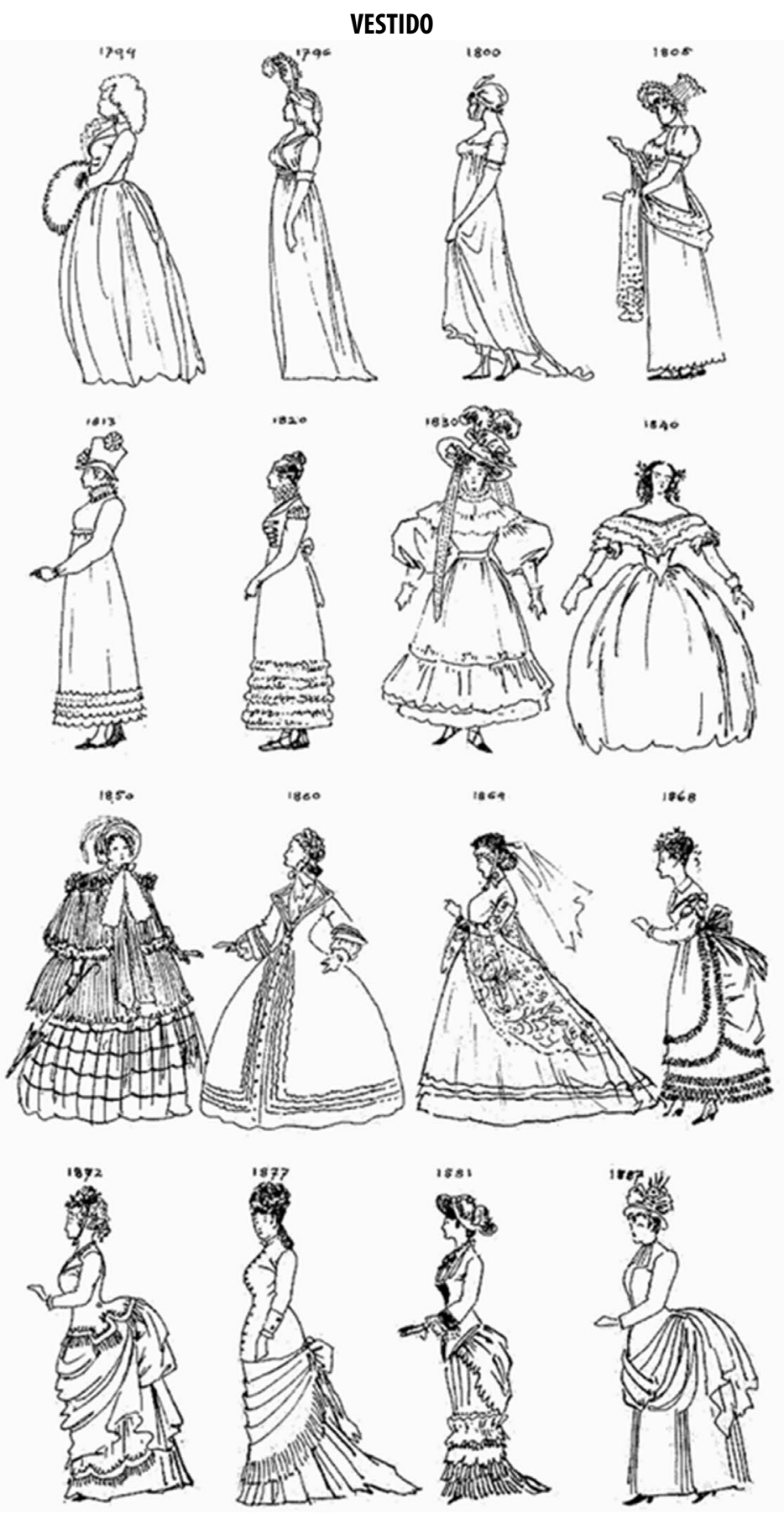

Fonte: disponível em: <http://www.endendademoda.com.br>. 